\title{
Selected Problems in Fine Needle Aspiration of Head and Neck Masses
}

\author{
Michael W. Stanley, M.D. \\ Department of Pathology, Hennepin County Medical Center, Minneapolis, Minnesota
}

\begin{abstract}
A wide variety of masses in the head and neck, including those in the major salivary glands, can be approached by fine needle aspiration. In many instances, a correct definitive diagnosis con be rendered after examination of smears or cell block material. However, several significant but uncommon areas can lead to diagnostic difficulties, with the potential for clinically important diagnostic errors. Many of these occur in salivary gland lesions. The most frequent problems involve variations in the expected cytology of pleomorphic adenoma. Then, there are several benign-malignant "look-alike" pairs of lesions. The first of these is related to smallcell epithelial neoplasms of low nuclear grade; the most frequent problem is between basal cell adenomas and adenoid cystic carcinoma, particularly the solid (anaplastic) type. The next area contrasts mucoepidermoid carcinoma with its cytologic mimic, benign salivary gland duct obstruction. The final difficulty in salivary gland aspiration contrasts large-cell epithelial lesions of low nuclear grade: oncocytic proliferations and acinic cell carcinoma. The clinical implications of cytologically benign squamous cell-containing cyst aspirates from the lateral neck will be discussed. Finally, a brief consideration of methodological optimization for thyroid aspirations will be offered.
\end{abstract}

Mod Pathol 2002;15(3):342-350

Masses in many head and neck sites are amenable to diagnosis by fine needle aspiration (FNA) cytology. After a brief consideration of general clinical principles of the method, this discussion will focus on areas in which significant diagnostic difficulties may arise. Several of these involve salivary gland sites and include the following: uncommon variations on the cytology of pleomorphic adenomas;

Copyright (C) 2002 by The United States and Canadian Academy of Pathology, Inc.

VOL. 15, NO. 3, P. 342, 2002 Printed in the U.S.A.

Date of acceptance: September 27, 2001.

Address reprint requests to: Michael W. Stanley, M.D., Department of Pathology-815, 701 Park Avenue, Minneapolis, MN 55415; e-mail: michael.stanley@co.hennepin.mn.us; fax: 612-904-4282. the differential diagnosis of small blue cell epithelial neoplasms; salivary gland aspirates that yield mucinous cystic contents; neoplasms that consist of monotonous large cells with eosinophilic cytoplasm and low-grade nuclear features; and squamous-lined cysts of the lateral neck. Finally, we will briefly consider issues in thyroid aspiration.

General Considerations in Fine Needle Aspiration of the Head and Neck

The diversity of masses in the head and neck and the differential diagnostic difficulties cited previously require that the best possible technique and preparations be employed. In general, the technique of needle aspiration is the same as that applied to other areas. We use 25-gauge $(0.5-\mathrm{mm})$ needles exclusively. We have also found that a $10-\mathrm{mL}$ syringe is quite adequate and that larger syringes do not produce better specimens. It is our practice to use a syringe holder in the Swedish manner, although others prefer the French technique of puncture without syringe aspiration. We have found that 25-gauge needles give adequate samples, and all of the cytologic material illustrated in this presentation was obtained with these small instruments.

We regard the preparation of aspirated material as a key step in optimizing diagnosis. We have found that the best results are obtained when the person performing the aspiration is also skilled in preparation of smears and allocation of material to cell blocks, or other studies as needed. This happens naturally in the type of practice in which a pathologist sees the patient and performs the aspiration. It is also possible to train physicians or clinic staff in these methods and thereby optimize the material that these individuals submit to the laboratory.

Most of our material is prepared as direct smears. This is in keeping with our literature's most frequent descriptions of aspiration cytology. Both airdried, Romanovsky-stained and fixed Papanicolaou-stained preparations have an important role in head and neck cytology. It is our goal to prepare 
both types of smears on virtually all cases. Cell blocks can also be very useful and are suitable for all histochemical and immunohistochemical special stains. The most frequent method of cell block preparation in our laboratory involves allowing hemorrhagic material to clot. This is then placed in neutral buffered formalin and handled as any small histologic specimen. Furthermore, we regard the need for cell block material as an indication for repeat FNA. This process is facilitated by immediate on-site review of rapidly stained smears.

FNA of head and neck sites has been studied extensively for several decades. The complication rate is extraordinarily low. Even after addressing large numbers of lesions in variably immunosuppressed individuals, we have seen no incidence of local aspiration site infection and have had no problems related to hemorrhage. Furthermore, the literature gives no instance of facial nerve damage in the case of parotid aspiration, despite the fact that this nerve courses through the substance of the gland.

Some have expressed fear of unknowingly encountering carotid body tumors in aspiration of neck masses. We have aspirated such lesions on a number of occasions and have experienced no complications. It seems that if one engages in aspiration of head and neck masses, eventually an unsuspected carotid body tumor will be encountered. At this point, it is useful to underscore the safety of performing this procedure with 25 -gauge needles.

\section{Difficult Differential Diagnoses in Salivary Gland Cytology}

Masses that appear clinically to be seated in the parotid gland may represent the gland itself, an intraparotid lymph node, a high cervical lymph node, or a cyst of the neck, or a soft tissue mass. Thus, given the clinical description of a parotid mass, one's differential diagnosis must be extremely broad. Complicating this clinical issue is the fact that secondary alterations of several types can be superimposed on a wide variety of salivary gland neoplasms. These include prominent lymphoid stroma, cystic change, clear cell change, oncocytic alterations, sebaceous differentiation, and mucin production. Thus, although the characteristic cytologic presentation of most common lesions is usually predictable, several confounding clinical and cytologic issues combine to make some fraction of aspirated cases very difficult to interpret.

Our classification of salivary gland aspirates is summarized in a detailed fashion in Table 1. This approach is based on one's first impression of an aspirate and the differential diagnostic considerations to which this will usually lead. As soon as a sample is taken or a smear is examined, it is possible to triage a case into one of several categories. From this, more detailed observation or extended investigation may lead to a more definitive classification. As discussed below, some differential diagnostic problems remain insoluble by cytologic means.

\section{Normal Salivary Gland Tissue}

Our first category is normal salivary gland tissue. In most instances, given the clinical impression of a mass, aspiration of only normal salivary gland elements indicates that the lesion has not been targeted accurately or has not given up material to the aspirating needle. However, in the proper clinical setting, it may be reasonable to consider a diagnosis of sialosis. The most important factor in making this diagnosis a reasonable consideration is the skill level and thoroughness of whomever has performed the aspiration. To say that a salivary gland enlargement does not represent a tumor based on aspiration of normal tissue elements requires a very high level of confidence in the procedure that has been performed.

The typical case of sialosis is bilateral and often associated with one of a variety of clinical considerations, including malnutrition, diabetes mellitus, or alcoholism. However, some cases are probably unilateral and idiopathic. Ultimate consideration of this diagnosis must rest in clinical hands.

The second type of aspiration is one that shows inflammation. In our experience, most aspirations yielding purulent material represent a secondary infection superimposed on sialolithiasis. Granulomas can be encountered in a variety of conditions. When chronic inflammatory cells are aspirated, one may consider an inflammatory process, aspiration of a regional lymph node, or hematopoietic neoplasm. In this setting, rapid interpretation of the smear material is very useful if one wishes to institute cultures or immunophenotypic investigation of lymphoid cells. However, it is important to recall that several salivary gland neoplasms can show prominent superimposed chronic inflammation.

When normal salivary gland tissue is aspirated, one can see both ductal and acinar elements. These are frequently present as large tissue particles containing both types of tissue and may be associated with adipose tissue. Ducts are tubular and may show branching. They are lined by a benign glandular epithelium similar to that in many other body sites. Acinar tissue shows basketlike arrangements of uniform cells with abundant granular or vacuolated cytoplasm and basally located, banalappearing nuclei. Many acinar cells will be damaged in the smearing process so that the slide background comes to be littered with naked round nuclei and granular cytoplasmic debris. The latter is more apparent in air-dried Romanovsky-stained 


\begin{tabular}{|c|c|c|c|}
\hline Initial Smear Pattern & Subclassification & $\begin{array}{l}\text { Diagnostic } \\
\text { Possibilities }\end{array}$ & Differential Diagnoses \\
\hline Normal tissue & - & Normal gland & Sialosis technical miss \\
\hline \multirow{10}{*}{ Inflammation } & Acute & & Nonspecific infection \\
\hline & & & Necrotic tumor \\
\hline & Chronic & & Reactive, NOS \\
\hline & & & Lymphoepithelial lesion \\
\hline & & Low-grade lymphoma & Tumor associated (MEC) \\
\hline & Granulomatous & & Infection \\
\hline & & & Sarcoidosis \\
\hline & & & Foreign body \\
\hline & & & Malignancy-associated (Low-grade MEC) \\
\hline & Stones & & \\
\hline \multirow[t]{4}{*}{ Pleomorphic adenoma } & Usual type & & \\
\hline & Myoepithelial type & & Plasmacytoma \\
\hline & & & Low-grade spindle cell \\
\hline & Complex or cellular & & Low-grade carcinoma \\
\hline \multirow[t]{3}{*}{ Warthin's tumor } & Usual type & & \\
\hline & Very little epithelium & & Cysts of several types \\
\hline & Atypical squamous cells & & Squamous cell carcinoma \\
\hline \multirow[t]{10}{*}{ Cyst } & Squamous cells & & $\begin{array}{l}\text { HIV-associated branchial cleft or other congenital } \\
\text { cysts }^{\text {b }} \text {, squamous cell carcinoma }\end{array}$ \\
\hline & & & Metastatic carcinoma \\
\hline & Mucoid & Obstructive & Stones \\
\hline & & Neoplastic & Low-grade MEC $^{\mathrm{a}}$ \\
\hline & Neoplastic & Benign & Pleomorphic adenoma \\
\hline & & & Warthin's tumor \\
\hline & & Malignant, primary & Acinic cell carcinoma \\
\hline & & & Low-grade MEC \\
\hline & & Malignant, metastatic & Squamous cell carcinoma \\
\hline & & & Papillary thyroid carcinoma \\
\hline \multirow[t]{7}{*}{ Epithelial, small cell } & & & Monomorphic adenoma \\
\hline & & & Adenoid cystic carcinoma \\
\hline & & & Small cell carcinoma \\
\hline & & & Metastatic carcinoma \\
\hline & & & Small cell \\
\hline & & & Basal cell \\
\hline & & & Nasopharyngeal \\
\hline \multirow{8}{*}{$\begin{array}{l}\text { Epithelial, large cell } \\
\text { low grade }\end{array}$} & & & Adenocarcinoma $^{\mathrm{a}}$ \\
\hline & & & Polymorphous low grade carcinoma \\
\hline & & & Acinic cell ${ }^{\mathrm{a}}$ \\
\hline & & & Oncocytic lesions $^{\mathrm{a}}$ \\
\hline & & & Squamous cell carcinoma \\
\hline & & & Clear-cell carcinoma ${ }^{\mathrm{a}}$ \\
\hline & & & Epithelial-myoepithelial carcinoma ${ }^{a}$ \\
\hline & & & Metastases \\
\hline \multirow{4}{*}{$\begin{array}{l}\text { Epithelial, large cell } \\
\text { high grade }\end{array}$} & & & High-grade MEC $^{a}$ \\
\hline & & & Squamous cell carcinoma \\
\hline & & & Ductal carcinoma \\
\hline & & & Metastases \\
\hline \multirow[t]{4}{*}{ Spindle cell, low grade } & & & Reactive, NOS \\
\hline & & & Nodular fasciitis \\
\hline & & & Hemangioma \\
\hline & & & Kaposi's sarcoma \\
\hline \multirow{4}{*}{$\begin{array}{l}\text { Spindle cell, high } \\
\text { grade }\end{array}$} & & & Primary sarcoma \\
\hline & & & Malignant melanoma \\
\hline & & & Squamous cell carcinoma \\
\hline & & & Metastases \\
\hline
\end{tabular}

${ }^{\text {a }}$ May show clear-cell change.

${ }^{\mathrm{b}}$ Includes branchial cleft, thyroglossal, and thymic cysts.

Some of these entities are not salivary gland lesions in the strict sense. However, they are included in the table for the sake of generating differential diagnoses for lesions that occur in this area. Clinically, it may be difficult to distinguish a cervical lymph node from a salivary gland lesion. Furthermore, some "parotid masses" are actually located in lymph nodes adjacent to or within the gland. MEC, mesoepithelial cell; NOS, not otherwise specified.

preparations than in fixed material. It is important that the naked nuclei of damaged acinar cells not be mistaken for lymphocytes. One should require a thin intact rim of basophilic cytoplasm before deciding that a cell is lymphoid in nature. Furthermore, the well-known lymphoid tangles and lymphoglandular bodies typical of lymphocyte-rich aspirations will not be present with smears of normal salivary gland tissue.

\section{Pleomorphic Adenoma and Warthin's Tumors}

The next two categories represent not only one's first impression but a final diagnosis. Most examples of pleomorphic adenoma and Warthin's tumor 
are readily recognized as such immediately upon study of rapidly stained material. In many instances, these two masses can be strongly suspected based on the patient's age and gender, as well as the findings at physical examination.

When pleomorphic adenomas are aspirated, they show various combinations of three elements: ductal cells, chondromyxoid matrix, and myoepithelial cells. The latter may be plasmacytoid or spindled. This combination of findings leads us to suggest that given a salivary gland aspiration with more than one component, pleomorphic adenoma is frequently the correct answer. In most instances, this cytologic diagnosis is straightforward, especially when coupled with the characteristic clinical presentation of this lesion.

It is reasonable to be concerned about the possibility of malignancy within a pleomorphic adenoma. However, this is very uncommon and rarely described in cytologic samples. Most examples that have been described in the FNA literature do not show both components, so that either a diagnosis of carcinoma without identification of the mixed tumor component or a false-negative diagnosis of benign mixed tumor is usually rendered.

In contrast to the case of malignancy in aspirates of mixed tumors, various alterations that may raise a potential suspicion of malignancy are rather common (1-4). The most frequent difficulty is with those examples yielding very little matrix and thus giving highly cellular smears. In some instances, most of these cells will be recognizably myoepithelial, and a diagnosis of pleomorphic adenoma or myoepithelioma will be rendered. In other instances, these tumors converge on the appearance of basal cell adenomas (see below).

The plasmacytoid type of myoepithelial cells can be pleomorphic and may occasionally show large nuclei and prominent nucleoli. In this setting, falsepositive diagnoses of various types of neoplasms may be considered, but the most common error is probably interpreting myoepithelial cells as plasmacytoma or malignant lymphoma (Fig. 1). Lesions that consist largely or exclusively of spindled myoepithelial cells also give rise to a variety of incorrect interpretations.

Abnormalities of ductal cells may also raise the suspicion of possible malignancy. Oncocytic change leads to dramatically enlarged ductal cells with nuclear pleomorphism and prominent nucleoli. Rounded collection of ductal cells arranged around a central lumen have been described as "cylindromatous" and are occasionally mistaken for adenoid cystic carcinoma (Fig. 2).

Any of these atypias found in association with other features diagnostic of mixed tumor should usually be tolerated, as pleomorphic adenoma is virtually always the correct diagnosis. However,

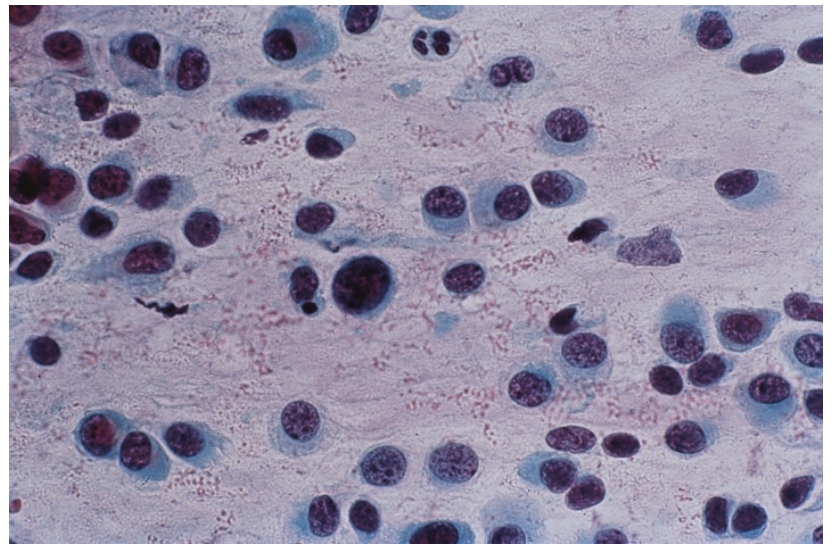

FIGURE 1. This smear from aspiration of a pleomorphic adenoma shows dispersed plasmacytoid and lymphocyte-like myoepithelial cells. These feature coarsely clumped chromatin, scanty cytoplasm, and occasional small nucleoli. This cytologic picture is sometimes mistaken for plasmacytoma or malignant lymphoma (Papanicolaou stain, $400 \times$ ).

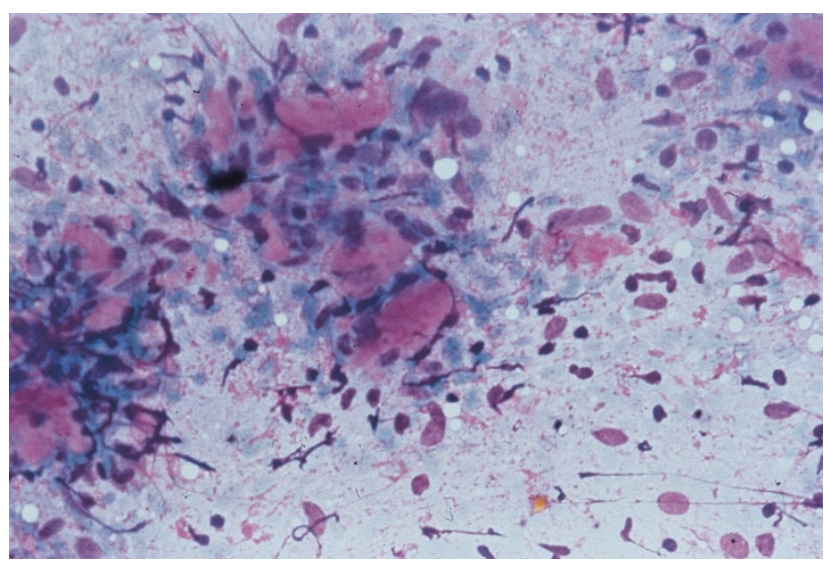

FIGURE 2. This smear from aspiration of a pleomorphic adenoma shows rounded fragments of metachromatic stromal material surrounded by small, darkly staining cells. This pattern is usually a focal finding in smear material otherwise characteristic of this tumor. This picture has led some to a mistaken diagnosis of adenoid cystic carcinoma (Diff-Quik stain, $400 \times$ ).

when these features are present to the exclusion of more diagnostic findings, a severe differential diagnostic difficulty may arise. In the series of Lee and colleagues (2), careful identification of plasmacytoid myoepithelial cells was the most helpful cytomorphologic feature for distinguishing pleomorphic adenoma from parotid malignancies, especially adenoid cystic carcinoma.

Pleomorphic adenoma has been investigated immunohistochemically (5-12). Of particular interest is the fact that $\mathrm{S}-100$ protein can be demonstrated in both epithelial and myoepithelial components. This is true of most pleomorphic adenomas, whereas normal salivary gland tissue and a variety of other lesions including chronic sialoadenitis, basal cell adenomas, adenoid cystic carcinomas, and low-grade mucoepidermoid carcinomas do not stain with this marker. Similar results have been 
obtained with immunostains for glial fibrillariocytic protein. However, limitation of these reagents' diagnostic utility lies in the fact that they primarily decorate the more chondroid areas of pleomorphic adenomas. Those neoplasms that clearly show this type of differentiation usually do not pose diagnostic difficulties and do not become the subject of immunohistochemical investigations.

Those tumors that consist mostly of myoepithelial cells share the same clinical presentation as more typical pleomorphic adenomas. Their cells may be not only plasmacytoid or spindled but may feature prominent clear-cell or oncocytic change. An immunoprofile showing positivity for vimentin, cytokeratins, S-100 protein, and GFAP may be diagnostically useful. Only the spindle cell type demonstrates smooth muscle actin (13).

Cytologic distinction between pleomorphic adenoma and the low-grade polymorphous adenocarcinoma has been little discussed in the cytology literature. In surgical pathology, this differential diagnostic distinction is extremely difficult in some cases unless infiltration at the tumor's periphery or perineural invasion are identified. We suggest that this distinction will remain extremely difficult in cytologic samples (14).

\section{Small-Cell Epithelial Neoplasms of Low Nuclear Grade}

Several salivary gland tumors are characterized by a proliferation of small blue cells that may be very uniform and feature bland nuclei. These include basal cell adenomas of various architectural types, pleomorphic adenomas with minimal chondroid matrix, adenoid cystic carcinoma (particularly the anaplastic, or solid type), basal cell adenocarcinoma, primary small cell carcinoma, and some examples of malignant lymphoma. By extension of this consideration to lesions that can occur near salivary gland sites but originate in other tissues, the list of small blue cell lesions may also include dermal eccrine cylindroma, pilomatrixoma, metastatic small cell anaplastic carcinoma, primary cutaneous Merkel's cell carcinoma, and metastases of cutaneous basal cell carcinomas. In many instances, clinical considerations will lead to the correct interpretation of what may initially be a cytologically confusing case.

None of the lesions just cataloged is common in FNA practice. However, in our opinion, difficulty with a small blue cell tumor that appears clinically to be seated in a salivary gland is the most frequent severe differential diagnostic problem that occurs in this site. On the basis of the relative frequencies with which each of these lesions is encountered, our experience leads us to indicate that the most common diagnostic dilemma is between basal cell adenoma and adenoid cystic carcinoma. This diffi- culty is most severe when one encounters adenoid cystic carcinoma with few of the metachromatic spheres and cylinders that are the celebrated cytologic hallmark of this tumor (15-21).

Both tumors generally yield highly cellular aspirates. These consist almost exclusively of uniform small blue cells with scanty cytoplasm. In most instances, cells from both lesions lack classic nuclear features of malignancy and in our opinion are frequently indistinguishable.

It has been suggested that details of the interface between these neoplastic cells and the tumor stromal components is a diagnostically useful feature. It has been noted that in the benign tumors, the cells interdigitate intricately with the fibrillary connective tissue associated with them. This is in contrast to the sharp interface between tumor cells and extracellular matrix material that forms the spheres and cylinders of adenoid cystic carcinoma. This diagnostic criterion is sometimes useful when one encounters a floridly cylindromatous adenoid cystic carcinoma with large quantities of typical extracellular basement membrane material. However, if this material is scanty, the utility of this diagnostic criterion is completely negated. One reason for this is that in these more anaplastic examples of adenoid cystic carcinoma, one frequently aspirates both the small blue cells and noncylindromatous connective tissue (Fig. 3). In these instances, the interface between tumor cells and the stroma will completely mimic that of basal cell adenoma. Furthermore, this type of stromal material may mimic the extracellular matrix of a pleomorphic adenoma.

Recognizing the extraordinary difficulty and severe clinical implications of this differential diagnostic difficulty, Lowhagen et al. (21) write as follows: "In our institution, we refuse to take the full diagnostic responsibility for a radical surgical procedure in which sacrifices of the facial nerve may be necessary in cases where there may be classic cytologic findings of adenoid cystic carcinoma, but the patient is symptom free."

It is difficult to envision an immunohistochemical solution to this problem. The epithelial cells of both tumors have been described as positive for cytokeratins, epithelial membrane antigen, and carcinoembryonic antigen. Results of immunostaining for S-100 have been more variable.

\section{Cystic Salivary Gland Aspirates}

When we previously considered the overall classification of salivary gland samples, we included the category of cystic aspirates and noted that some of these are mucoid. Although cystic change can be associated with a variety of salivary gland lesions, the most frequent differential diagnostic difficulty occasioned by a cyst aspirate that appears mucinous will be between a nonneoplastic duct- 

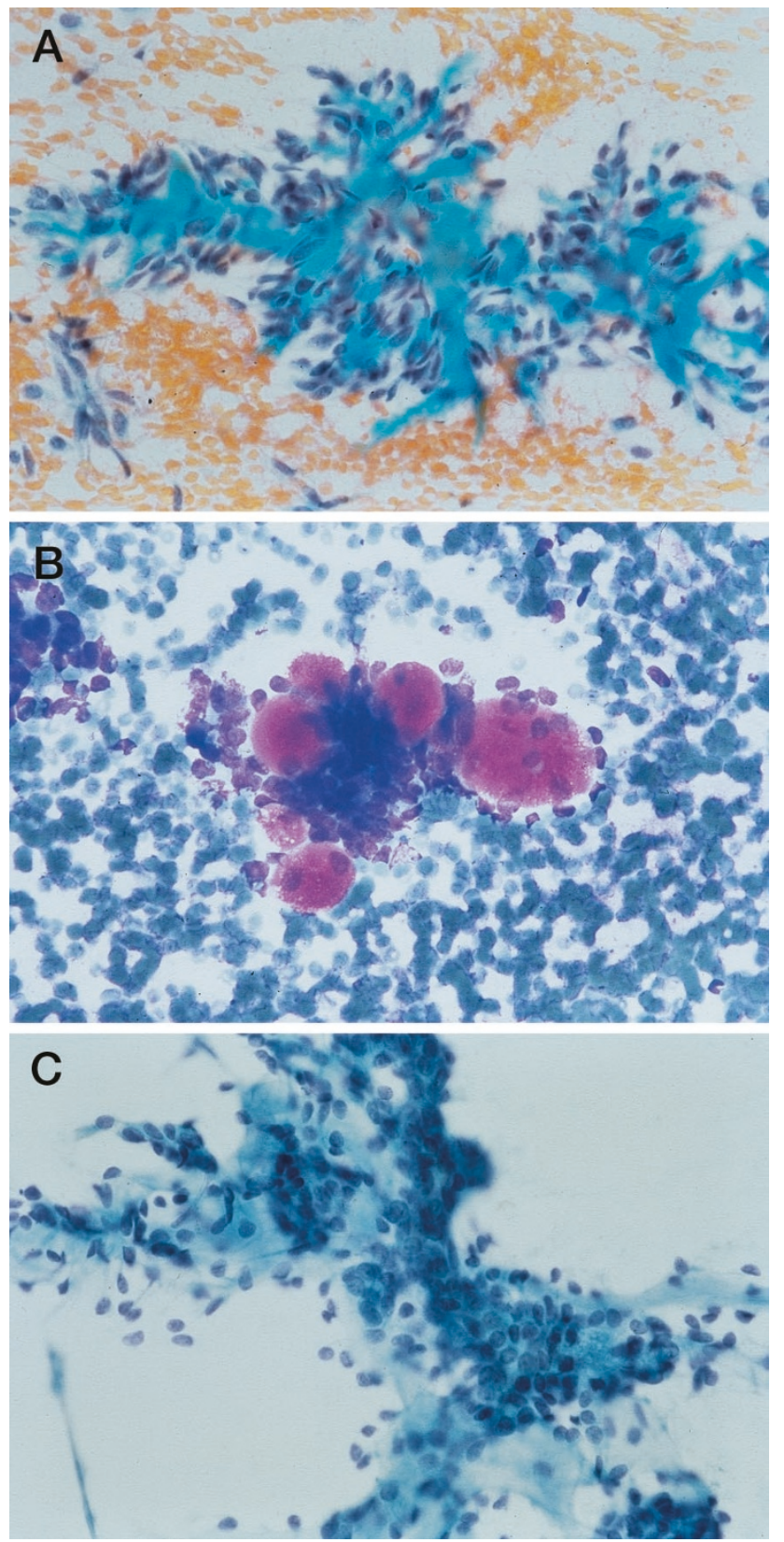

FIGURE 3. These images highlight the difficulty that one can experience in distinguishing between aspiration from a basal cell adenoma and those of some adenoid cystic carcinomas. A, this smear from a basal cell adenoma shows arborizing collagenous stroma decorated by small, uniform, darkly staining cells. These cells interdigitate intricately with the stroma (Papanicolaou stain, $100 \times$ ). B, the typical cytology of adenoid cystic carcinoma is shown here. This features extracellular spheres of metachromatic basement membrane material. The small, uniform, darkly staining cells that surround these spheres are sharply demarcated from the extracellular material. This latter feature is in contrast with the interdigitation of cells and stroma shown in Figure 3A (Diff-Quik stain, 100×). C, this image highlights the difficulty that one can experience in distinguishing between this adenoid cystic carcinoma and basal cell adenoma illustrated in Figure 3A. The cells of this carcinoma show none of the traditional cytologic features of malignancy and have an intricate interdigitating relationship with the extracellular stroma (Papanicolaou stain, $100 \times$ ).

obstructive lesion and low-grade mucoepidermoid carcinoma (22). It is important to recall that either of these may be associated with a substantial chronic inflammatory component. Acute inflammation is usually not encountered, except in the setting of a duct-obstructive lesion with superimposed bacterial infection. In this instance, needle aspiration is not likely to be requested.

The dilated ducts of an obstructed lesion undergo epithelial metaplasia that leads to a combination of squamous, squamous metaplastic, and mucinous cells. This is associated with duct dilatation by secretory material and acinar atrophy. Aspiration of either this of type lesion or low-grade mucoepidermoid carcinoma will show sparsely cellular material rich in extracellular mucous. When cell clusters are encountered, these tend to be cohesive and to show no nuclear features of malignancy (Fig. 4). Degenerative change can be superimposed on either lesion. In our experience, some aspirates from benign duct-obstructive lesions are paradoxically more cellular than those of low-grade carcinomas. They may also show more cytologic atypia and are sometimes shed in a better state of preservation.

A particular case of the more generally described duct-obstructive lesion is sialolithiasis (23). The typical patient is female and has a submandibular gland swelling. Most patients can give symptoms of pain and swelling in the area at meal times. Some stones are radiographically visible, but a substantial minority are not. When one sees aspirate material from a sialolithiasis patient, it will have come from an individual who presents in the absence of these characteristic clinical findings. Thus, the small minority of these patients who have fine needle aspirations present with a firm mass and no symptoms suggestive of the correct diagnosis. In this setting,

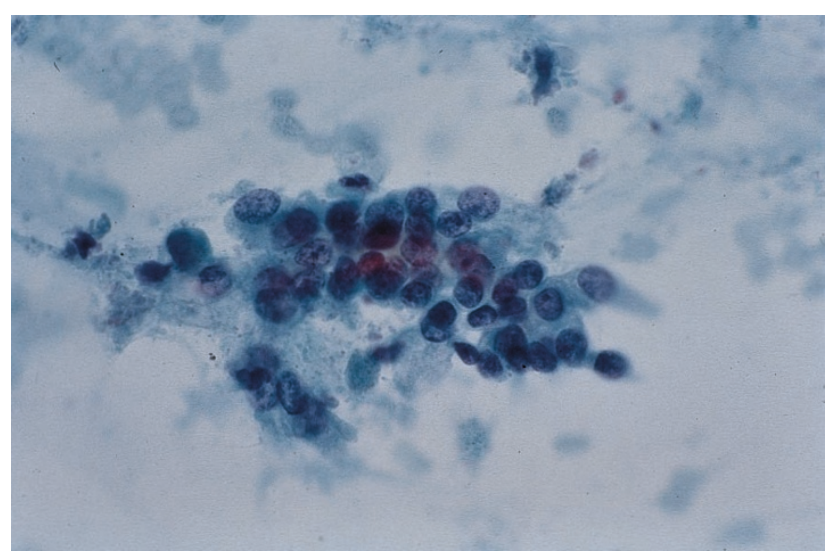

FIGURE 4. This aspiration from a benign salivary gland ductobstructive lesion due to sialolithiasis shows a background of mucous with scattered clusters of epithelial cells. Paradoxically, such cell clusters may be more numerous in aspirations of duct-obstructive lesions than in smears prepared from the mucoepidermoid carcinomas. Furthermore, duct-obstructive lesions may yield greater degrees of cytologic atypia than is frequently noted in mucoepidermoid carcinoma aspirations. In this example of a benign duct-obstructive lesion, this cell cluster shows nuclear crowding with loss of orientation and a tendency toward chromatin clumping and clearing (Papanicolaou stain, $400 \times)$. 
what we see is a small minority of highly selected patients in whom we are clinically led to consider a neoplastic process.

At the time of needle aspiration, there are two findings that can point to the correct diagnosis of sialolithiasis and allow one to avoid a false diagnosis of low-grade mucoepidermoid carcinoma. If stone fragments are present, the diagnosis is usually straightforward. Another finding in some ductobstructive lesions of various etiologies is ciliated metaplasia of the ductal cells. The general cytology rule that cilia should always lead to a benign diagnosis applies in this instance. In the absence of these features, it can be difficult or impossible to distinguish low-grade mucoepidermoid carcinoma from a benign duct-obstructive lesion. In this case, there is another important clinical consideration. We have seen the duct-obstructive pattern in patients whose superficial parotid lobe is compressed by a deep lobe tumor or even by a mass extrinsic to the salivary gland. For this reason, even identification of cilia should not be allowed to truncate the needed clinical evaluation.

An additional exception to the cautions that we have sounded when dealing with mucinous salivary gland aspiration involves children. Low-grade mucoepidermoid carcinoma is the most common salivary gland malignancy in this patient population. However, as a rule, children do not suffer from most of the conditions that lead to benign ductobstructive lesions, including sialolithiasis. Thus, the characteristic picture of mucoepidermoid carcinoma in a child should usually lead to this diagnosis.

Finally, the presence of chronic inflammatory cells, even in great numbers, does not alter the diagnostic dilemma we have described. Lymphoid tissue can be a prominent component of either duct-obstructive lesions or mucoepidermoid carcinoma.

\section{Large-Cell Epithelial Neoplasms of Low Nuclear Grade}

The final category of salivary gland diagnostic difficulties involves those that feature relatively large cells with abundant cytoplasm and low-grade nuclear features. This family of lesions can include oncocytic proliferations, acinic cell carcinoma, sebaceous neoplasms, clear-cell carcinoma, epithelial-myoepithelial carcinoma, polymorphous lowgrade adenocarcinoma, and various metastatic lesions. Several of these are uncommon and remain largely unaddressed in the FNA literature. However, distinction between oncocytoma and acinic cell carcinoma occasionally arises as a clinical problem (24-26). In cytologic samples, both are characterized by highly cellular preparations with fairly uniform large cells. These feature abundant granular cytoplasm. In the smear background, there are always numerous naked nuclei and abundant granular cytoplasmic debris (Fig. 5).

In many instances, the consequences of making an incorrect diagnosis will be limited, as the surgical approach to both lesions is similar. It is important to recall that acinic cell carcinoma can recur many years after the initial diagnosis, so requests for evaluation of a needle aspiration specimen may arrive without adequate clinical information. Clearcell change may be superimposed on either of these neoplasms and broadens the differential diagnosis considerably. In some patients, one will need to exclude the possibility of metastatic renal cell carcinoma.

If necessary, ultrastructural studies can distinguish the oncocytes' granularity caused by mitochondria from that of acinic cell carcinoma, in which granularity is due to zymogen material. Both of these neoplasms appear granular cytologically. However, we have sometimes noted on cell block sections that the typical histologic appearance of zymogen granules is much better represented than
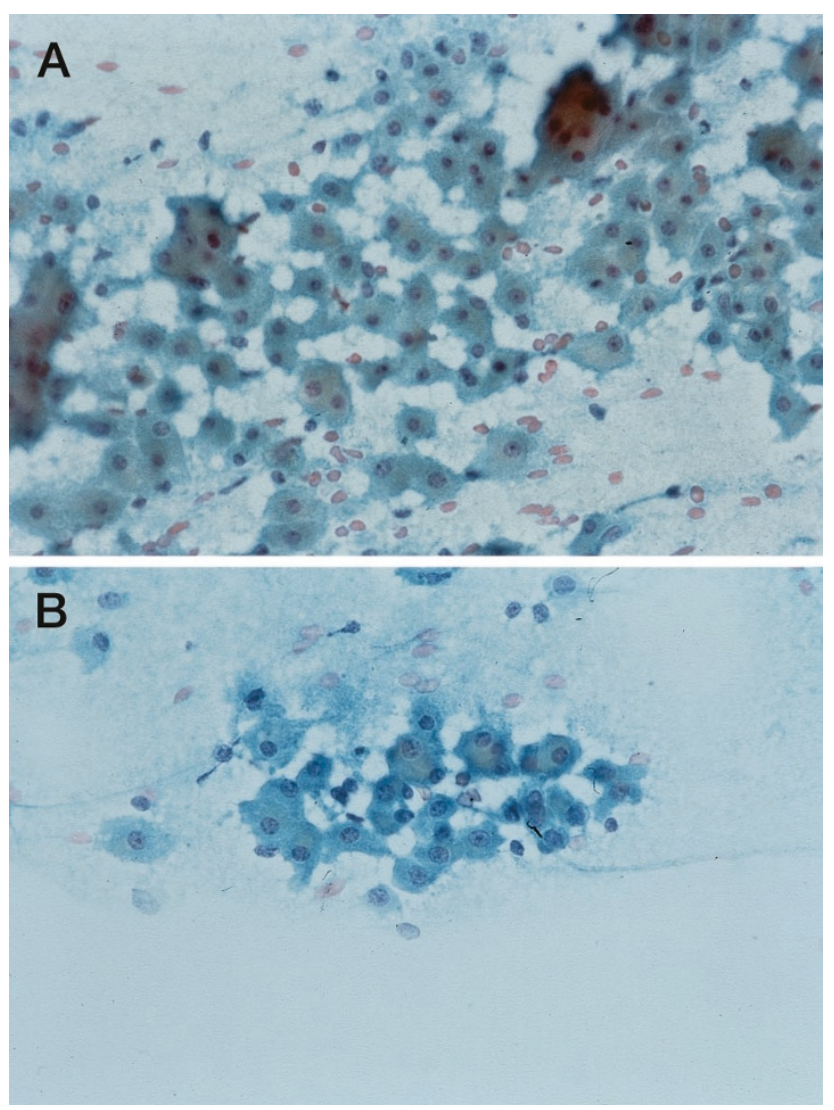

FIGURE 5. These images contrast the cytologic presentation of oncocytoma and acinic cell carcinoma in smear material. A, this oncocytoma yields a highly cellular aspirate. A background of granular debris represents cytoplasm of cells damaged in the smearing process. These cells are loosely cohesive, with a low nucleocytoplasmic ratio and occasional prominent nucleoli (Papanicolaou stain, $100 \times$ ). B, this aspiration from an acinic cell carcinoma is virtually indistinguishable from the previously illustrated oncocytoma (Papanicolaou stain, 100×). 
smear preparations. Superimposed cystic change on either neoplasm may further broaden the differential diagnostic possibilities. When metastatic thyroid carcinoma is considered, thyroglobulin immunostains are very useful.

\section{Squamous Cysts of the Neck}

When one encounters midline cysts with squamous cells, lymphoid tissue, and various other epithelial elements, it is often safe to assume that these represent developmental lesions. However, when squamous-lined cysts of the lateral neck are considered, the distinction between a congenital cyst and a metastatic squamous cell carcinoma with cystic change can be difficult or impossible to make with confidence. Furthermore, not all branchial cleft cysts are in the characteristic location. They can be encountered in a number of sites. First branchial-cleft developmental abnormalities can give rise to lesions in or around the external auditory canal.

The cytopathologist's problem lies in the fact that some cystic metastases of squamous cell carcinoma yield only very well-differentiated, matureappearing squamous cells at the time of FNA. In the absence of clear-cut cytologic evidence of malignancy, one is left with a squamous lined cyst that may be deceptively bland (27). It is tempting to speculate that patients who are at minimal risk for carcinoma can be identified based on age. When one is dealing with children, this is probably true. However, in some cultures, many individuals begin active cigarette smoking at a very early age, so that squamous cell carcinomas can be encountered in patients in their 20s and 30s. Thus, it is probably wise to at least consider excision of any squamouslined cyst of the lateral neck in any patient other than a young child.

\section{Thyroid Aspiration}

A detailed consideration of thyroid cytology and its clinical indications and follow-up is beyond the scope of this presentation. However, some technical consideration can improve the laboratory's success in dealing with thyroid aspirations.

Most lesions of the thyroid can be best approached by having the patient supine, with a pillow elevating the shoulders. When the neck is hyperextended, most nodules rise to lie most superiorly and more anteriorly in the palpable neck. In this manner, they are easily located in the gutter between the sternocleidomastoid muscle and the trachea. The needle should always be directed medially. This insures that no structures in the neck can be inadvertently punctured except the trachea. All individuals who frequently perform thy- roid aspiration eventually puncture the trachea. When this happens, the patient may cough and the operator immediately has the sensation of losing vacuum in the syringe. In our experience, this is uniformly without clinical consequences.

The thyroid is another area in which we emphasize the practical utility of very thin needles. We always employ 25-gauge needles. It is frequently difficult to distinguish a cystic from a solid lesion by physical examination. We prefer to enter a thyroid nodule very gently and await the return of cyst fluid. If this does not occur, one may then initiate the usual sampling motion of the needle. If, however, this motion is initiated immediately upon entering a cystic lesion, hemorrhage frequently occurs, and although some fluid is withdrawn, the lesion refills immediately under the operator's fingertips. Because the goal of cyst aspiration is complete removal of the fluid or reaspiration of any residual mass after attempted cyst drainage, having the cyst refilled with fresh blood defeats much of the purpose of thyroid cyst aspiration.

Diagnostically, most thyroid aspirations represent benign colloid nodules. The quantity of colloid vs. the number of cells is often the most important diagnostic finding. Colloid is very easily demonstrated and quantitated on air-dried preparations, and it is for this reason that we prefer to do most thyroid cytology with this type of material. Furthermore, in our experience, many clinicians who aspirate the thyroid do a very poor job of fixing slides for Papanicolaou staining. Thus, the often-cited nuclear features demonstrated by the Papanicolaou stain are not available, even when this method is applied.

The literature regarding new liquid-based preparatory methods as applied to thyroid fine needle aspiration samples has described relatively few cases to date, and experience has been variable (28-31). Most recently, Nasuti and coworkers have indicated substantial diagnostic difficulties when the ThinPrep device has been applied to the thyroid FNAs as the only preparatory method (31).

\section{REFERENCES}

1. Elsheikh TM, Bernacki EG. Fine needle aspiration cytology of cellular pleomorphic adenoma. Acta Cytol 1996;40:1165-75.

2. Lee SS, Cho KJ, Jang JJ, Ham EK. Differential diagnosis of adenoid cystic carcinoma from pleomorphic adenoma of the salivary gland on fine needle aspiration cytology. Acta Cytol 1996;40:1246-52.

3. Viguer JM, Vicandi B, Jimenez-Heffernan JA, Lopez-Ferrer P, Limeres MA. Fine needle aspiration cytology of pleomorphic adenoma. An analysis of 212 cases. Acta Cytol 1997;41:78694.

4. Takeda Y. An immunohistochemical study of bizarre neoplastic cells in pleomorphic adenoma: its cytological nature and proliferative activity. Pathol Int 1999;49:993-9. 
5. Dardick I, Stratis M, Parks WR, DeNardi FG, Kahn JH. S-100 protein antibodies do not label normal salivary gland myoepithelium: histogenetic implications for salivary gland tumors. Am J Pathol 1991;138:619-58.

6. Nishimura T, Furukawa M, Kawahara E, Miwa A. Differential diagnosis of pleomorphic adenoma by immunohistochemical means. J Laryngol Otol 1991;105:1057-60.

7. Hirano T, Kashiwado I, Suzuki I, Yoshihiro T, Yuge K, Asano G. Immunohistopathological properties of pleomorphic adenoma in salivary gland. J Nippon Med School 1990;57: 172-9.

8. Anderson C, Knibbs DR, Abbott SJ, Pedersen C, Krutchkoff D. Glial fibrillary acidic protein expression in pleomorphic adenoma of salivary gland: an immunoelectron microscopic study. Ultrastruct Pathol 1990;14:263-71.

9. Ostrzega N, Cheng L, Layfield L. Glial fibrillary acidic protein immunoreactivity in fine-needle aspiration of salivary gland lesions: a useful adjunct for the differential diagnosis of salivary gland neoplasms. Diagn Cytopathol 1989;5:145-9.

10. Takahashi H, Tsuda N, Tezuka F, Okabe H. Immunohistochemical localization of carcinoembryonic antigen in carcinoma in pleomorphic adenoma of salivary gland: use in the diagnosis of benign and malignant lesions. Tohoku J Exp Med 1986;149:329-40.

11. Takeda Y, Shimono M. Pleomorphic adenoma with nuclear palisading arrangement of modified myoepithelial cells: histopathologic immunohistochemical study. Bull Tokyo Dent Coll 1999;40:27-34.

12. Felix A, Rosa JC, Fonseca I, Cidadao A, Soares J. Laminin and collagen IV in pleomorphic adenoma and carcinoma expleomorphic adenoma: an immunohistochemical study. Hum Pathol 1999;30:964-9.

13. Franquemont DW, Mills SE. Plasmacytoid monomorphic adenoma of salivary glands: absence of myogenous differentiation and comparison to spindle cell myoepithelioma. Am J Surg Pathol 1993;17:146-53.

14. Gibbons D, Saboorian MH, Vuitch F, Gokaslan ST, Ashfaq R. Fine-needle aspiration findings in patients with polymorphous low grade adenocarcinoma of the salivary glands. Cancer 1999;87:31-6.

15. Stanley MW, Horwitz CA, Bardales RH, Stern SJ, Korourian S. Basal cell carcinoma metastatic to the salivary glands: differential diagnosis in fine-needle aspiration cytology. Diagn Cytopathol 1997;16:247-52.

16. Stanley MW, Horwitz CA, Henry MJ, Burton LG, Lowhagen T. Basal-cell adenoma of the salivary gland: a benign adenoma that cytologically mimics adenoid cystic carcinoma. Diagn Cytopathol 1988;4:342-6.

17. Stanley MW, Horwitz CA, Rollins SD, Powers CN, Bardales $\mathrm{RH}$, Korourian S, et al. Monomorphic and minimally pleomorphic adenomas of the salivary glands (SG): distinction from the solid (anaplastic) type of adenoid cystic carcinoma in fine needle aspiration (FNA). Am J Clin Pathol 1996;106: 35-41.

18. Yu GH, Caraway NP. Poorly-differentiated adenoid cystic carcinoma: cytologic appearance in fine-needle aspirates of distant metastases. Diagn Cytopathol 1996;15:296-300.

19. Nagel H, Hotze HJ, Laskawi R, Chilla R, Droese M. Cytologic diagnosis of adenoid cystic carcinoma of salivary glands. Diagn Cytopathol 1999;20:358-66.

20. Kapadia SB, Dusenbery D, Dekker A. Fine needle aspiration of pleomorphic adenoma and adenoid cystic carcinoma of salivary gland origin. Acta Cytol 1997;41:487-92.

21. Lowhagen T, Tani EM, Skoog L. Salivary glands and rare head and neck lesions. In: Bibbo M, editor. Comprehensive cytopathology. Philadelphia: Saunders; 1991. p. 627-34.

22. Klijanienko J, Vielh P. Fine-needle sampling of salivary gland lesions. IV. Review of 50 cases of mucoepidermoid carcinoma with histologic correlation. Diagn Cytopathol 1997;17: $92-8$.

23. Stanley MW, Bardales RH, Beneke J, Korourian S, Stern SJ. Sialolithiasis. Differential diagnostic problems in fine-needle aspiration cytology. Am J Clin Pathol 1996;106:229-33.

24. Skalova A, Starek I, Michal M, Leivo I. Malignancysimulating change in parotid gland oncocytoma following fine needle aspiration. Report of 3 cases. Pathol Res Pract 1999;195:399-405.

25. Nagel H, Laskawi R, Buter JJ, Schroder M, Chilla R, Droese M. Cytologic diagnosis of acinic-cell carcinoma of salivary glands. Diagn Cytopathol 1997;16:402-12.

26. Klijanienko J, Vielh P. Fine-needle sample of salivary glands lesions. V: Cytology of 22 cases of acinic cell carcinoma with histologic correlation. Diagn Cytopathol 1997;17:347-52.

27. Burgess KL, Hartwick RW, Bedard YC. Metastatic squamous carcinoma presenting as a neck cyst. Differential diagnosis from inflamed branchial cleft cyst in fine needle aspirates. Acta Cytol 1993;37:494-8.

28. Biscotti CV, Hollow JA, Toddy SM, Easley KA. ThinPrep versus conventional smear cytologic preparations in the analysis of thyroid fine-needle aspiration specimens. Am J Clin Pathol 1995;104:150-3.

29. Frost AR, Sidawy MK, Ferfelli M, Tabbara SO, Bronner NA, Brosky KR, et al. Utility of thin-layer preparations in thyroid fine-needle aspiration: diagnostic accuracy, cytomorphology, and optimal sample preparation. Cancer 1998;84:17-25.

30. Scurry JP, Duggan MA. Thin layer compared to direct smear in thyroid fine needle aspiration. Cytopathology 2000;11: 104-15.

31. Nasuti JF, Tam D, Gupta PK. Diagnostic valve of liquid-based (ThinPrep) preparations in nongynecologic cytology. Diagn Cytopathol 2001;24:137-41. 